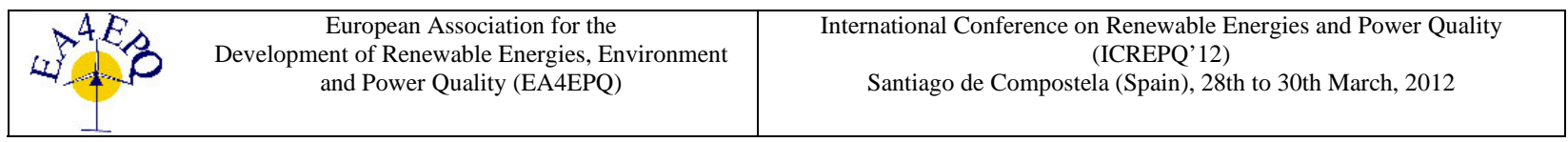

\title{
Iran's Participatory Power Market Regarding Distributed Generation from Renewable Sources: A Case Study
}

\author{
A.M. Motavaselian ${ }^{1}$, A.R. Faghih Khorasani ${ }^{2}$ \\ ${ }^{1}$ Yazd Pars-ris Company \\ P.O. No.: 8918796145 Yazd (Iran) \\ Phone/Fax number: +98 351 5252634, e-mail: Ali.motavaselian@gmail.com \\ ${ }^{2}$ School of Mechanical Engineering \\ Faculty of Engineering, Yazd University, P.O. Box: 89195-741 Yazd (Iran) \\ Phone number: +98 351 8122561, Fax number: +98 351 8210699, Faghih@yazduni.ac.ir
}

\begin{abstract}
To study initial conditions for participatory power market formation based on renewable energy sources (RES) in Iran after complete accomplishment of the economic evolutionary plan, a case study for a residential building has been conducted to consider the effects of the most important parameters. So, a model of power market including three parts: consumption, production and regulations, has been optimized to achieve to a micro cost effective system of participatory power market regarding distributed generation from RES. The results indicate that the power tariff structure and rates, RES technology capital cost and economic conditions are prominent parameters. As well, to initiate the power market, a revised power tariff structure and rates are suggested; namely, a plan for shifting peak load hours from evening to day hours is essential. Also, it is demonstrated that the policy of establishing a participatory power market included photovoltaic distributed generation systems must be pursued in the economic evolutionary plan with emphasis on development of zero energy cost buildings.
\end{abstract}

\section{Key words}

Participatory power market, distributed generation, photovoltaic systems, emission costs, power tariffs

\section{Introduction}

Energy is one of the most challenging issues of our world. As electric and electronic tools get more involved in our life, electricity provision becomes more important. To achieve a balanced pattern of electricity production and consumption, a large number of parameters must be considered. Techno-economic issues like reduction of production and transmission costs and promotion of technologies of electricity production, especially those of which relate to the renewable energy sources (RES), are one domain of concern. Acts and directives of power market which address management and policy considerations are another field of influence. Moreover, environmental considerations are going to be prominent decision parameter in energy sector. On the other hand, many efforts and innovations are underway to deal with these concerns. Distributed generation (DG), renewable energy technologies and participatory power market are some worldwide solutions toward an appropriate model of electricity supply and demand. To advance such a model, legions of calculations and considerations must take into account to address technical complexities and infrastructural restrictions. A review of technical, commercial and environmental drivers, challenges and opportunities for DG systems has been made by Pecas Lopes et al. [1]. Kowalski et al. advanced a comprehensive method in order to develop renewable energy scenarios for sustainable energy futures [2]. Also, various studies have been conducted about different approaches to power market formation and its effects on energy trade, worldwide ([3]-[6]). But, is there any intermediate approach to deal with the current transitory period?

Iran's power market, which has annual production capacity of $56200 \mathrm{MW}$ including 20 percent contribution of renewable sources, mainly hydroelectric, suffers from 20 percent transmission and distribution losses[7]. Electricity production industry in Iran traditionally is based on an uncompetitive environment which rules by the government and works not so efficient. Nearly from the beginning of 2011 Iran began to implement an economic evolutionary plan to promote competitive environment in domestic markets, as one of the main targets. First step has been taken by accomplishment of targeted subsidy plan. According to the plan, during five years, prices of energy carriers in Iran approximately reach to world energy prices level. Specifically about electricity, it will be sold with the cost of average electricity production. Due to the significance of energy issues, Iran places on the agenda to move toward privatization and participation in power market with emphasis on the deployment of renewable energy 
sources, along with the world. During the past years there had been a lot of diverse efforts to transform Iran's power industry but minor tangible results have been achieved due to the lack of comprehensive energy legislation [8].

This paper discusses important initiatives of a participatory power market profited by renewable DG systems, under Iran's circumstance. To pursue the policy of development of renewable DG systems in order to promote the quality of electricity grid, first step is providing incentives for RES technology investors and second step is to provide efficient mechanism to encourage renewable DG systems connect to the electricity grid. So, the objective of this work is to study the effects of the major decision variables of a model of participatory power market on feasibility of embarking such a market regardless of technical complexities of the electricity grid.

\section{Methodology}

Since providing a deliberate and practicable plan needs extensive computations and considerations to take into account technical complexities and infrastructural constraints, we have taken a bottom-up approach to attack the problem. The model used consists of three parts: consumption, production and applicable regulations. To highlight minimum desired conditions for initiating a participatory power market including distributed generation from the RES, the most practicable case for Iran's condition has been considered. So a single dwelling house in Tehran-Mehrabad region at latitude of $35.7^{\circ} \mathrm{N}$ and elevation of 1220 meters above sea level has been considered to use photovoltaic system besides electricity grid to facilitate market formation. It means that residential sector which has the most diverse and numerous consumption units with low energy intensity best fitted to the policy of distributed generation from the RES; as well, solar energy is the most probable choice of RES for electricity production because it is the most viable case for the country which has dry climate and receives considerable amount of solar irradiance in the most areas [9]. Moreover, the third and probably the most complex part of the model consist of all applicable rules of energy trade including environmental considerations.

\section{A. Consumption}

According to the domestic statistics, residential sector has a great contribution in the total electricity consumption; unfortunately often due to the energy losses occur because of weak designed and constructed buildings and using inefficient appliances [7]. Generally, first step toward RES utilization is decreasing energy consumption intensity because of lower energy intensity of RES relative to traditional energy sources. In this way, deployment of new energy technologies scaled for residential application would be possible. On the other hand, regarding plethora of residential consumption terminals, there would be a great potential for distributed generation especially from solar energy, the fact which is confirmed by IEA reports [10]. Zero Energy Buildings (ZEB) is a proposed approach for promoting energy consumption standards. This concept has been used to investigate eventual effects of energysaving incentives on participatory power market structure.
In fact, the objective is to study how well improved consumption patterns can help power market formation, or conversely, how participatory power market formation can help us to achieve predefined targets for rational energy consumption patterns.

\section{B. Production}

Due to the permeated electricity grid into almost all urban areas of Iran and great contribution of urban dwellings in electricity consumption, national grid would be a default choice for energy supply. Moreover, it can be contributed in energy storage through emerging designs. The notion of on-grid photovoltaic systems have ever increasing trend worldwide and could be the second choice for electricity supply to work integrated to the grid[11]. One of the difficulties with residential PV system utilization is mismatch profiles of production and consumption. While most of electricity production occurs at daytime, peak energy consumption occurs at night due to the lights and appliances in use whilst PV system has no output. In addition to the mismatch problem, stringent dependence of PV module efficiency to solar incident and high investment cost of PV systems are prevailing issues of photovoltaic system application. According to the world data, 23 out of 37 TWh of solar electricity in 2010 was produced by residential sector[10]; as well, to achieve grid parity in residential sector more than 50 percent reduction of PV system capital cost from $6 \$ / \mathrm{W}_{\mathrm{p}}$ in 2008 to $2.7 \$ / \mathrm{W}_{\mathrm{p}}$ in 2020 needs to occur[11].

\section{Regulations}

Accomplishment of the energy plans needs legislations to regulate exchange in power market. Power tariff regulations may be the most effective one. Since time and price are two important parameters in energy trade, revision of existing power tariffs is inevitable because solar electricity would cost more than grid electricity. Although, Iran has feed-in-tariff directive [12] but this non-incentive directive belongs to the time before the targeted subsidy plan. So, more sophisticated tariffs are necessary part of power market. Current state of residential power tariff in Iran is based on partial subsidies prices scheduled for four hours a day as peak time and four hours a day as off-peak time and the rest regarded as shoulder time. Also, base rates are weighted by summer factor (four months a year) and winter factor (three months a year) to take into account seasonal variations in different parts of the country. Currently, peak hours are considered to be between 19 and $23 \mathrm{pm}$ and off-peak hours are considered to be 1 to $5 \mathrm{am}$. Figure 1 shows the current schedule for Iran's residential power tariffs, it has been regarded as reference power tariff structure. In the reference case, which is based on conventional power meters, only peak and off-peak rates are considered, it means that rate of shoulder time and peak time are considered to be the same and 50 percent discount is devoted to assumed off-peak hours which are after midnight. So, existing residential power tariffs don't draw any distinguishing line between peak and shoulder rates. 


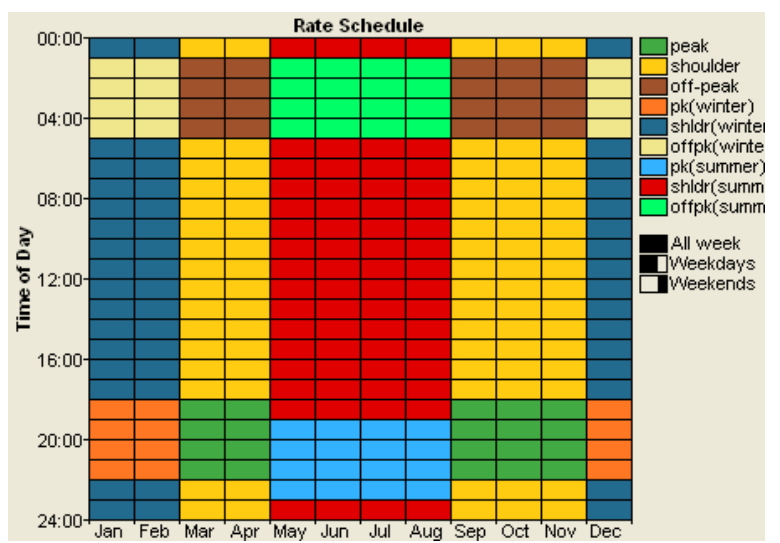

Fig. 1. Existing power tariff structure

To examine the efficacy of structure of power tariffs, peak hours will move to daytimes which imply the situation that the productive parts of the country such as industry and commercial sectors would have greater shares of total electricity consumption. Furthermore, different sellback rates are scrutinized to determine an appropriate range for feed-in-tariff. To do so, a new rating is proposed so as peak rate is 1.5 times the shoulder rate and shoulder rate is 2 times the off-peak rate which needs multi-tariff power meters (Fig. 2).

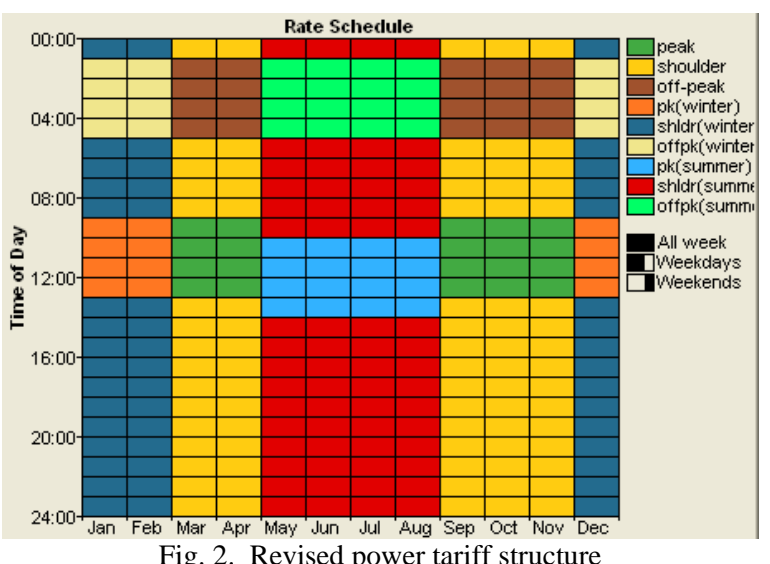

Another concern is environmental restrictions. With regard to high level of emission from fossil fuelled power plants than distributed generation from the RES, taking into account emission costs would be in favour of development of renewable energy technologies. Table 1 includes average emission rates and costs of different pollutants from Iran's power plants.

Table I. - Emission data [7]

\begin{tabular}{|c|c|c|}
\hline Emission Type & Cost(\$/ton) & $\begin{array}{c}\text { Grid } \\
\text { Emission rate } \\
\text { (gr./kWh) }\end{array}$ \\
\hline Carbon dioxide & 24 & 692 \\
\hline Carbon monoxide & 45 & 1 \\
\hline PM & 10000 & 0.1 \\
\hline Sulfur dioxide & 4400 & 2.84 \\
\hline Nitrogen oxide & 1400 & 2.63 \\
\hline
\end{tabular}

Indeed, implementing environmental restriction is useful for both the participatory power market formation and global warming and climate change considerations. So, in the second scenario both revised power tariff structure and emission costs will be considered. Clearly, in the case of PV system utilization avoided emission costs will be taken into account as negative operating cost.

\section{Techno-Economic Analysis}

To perform required analysis, available optimization software which is capable of considering all of the mentioned parameters and variables is chosen. HOMER 2.81 software [13] has the capability of doing detailed analysis which is suitable for the proposed model and gives quiet indicative outputs and graphs. The model consists of an hourly electrical load profile, grid, PV system, and converter and battery bank. The software computes cost of different combinations of model components at predefined capacities and categorizes them in terms of cost efficiency. As reference values, main parameters of the model are shown in Table 2. It is necessary to mention that the grid power rates are assumed to be free from subsidy at the condition of complete implementation of the targeted subsidy plan and sellback rates are considered to be 1-5 times the grid power rates.

Table II. - Reference Values

\begin{tabular}{|c|c|}
\hline Parameter & $\begin{array}{c}\text { Reference } \\
\text { value }\end{array}$ \\
\hline Average clearness index[14] & 0.591 \\
\hline $\begin{array}{c}\text { Average daily load[15] } \\
\text { (kWh/day) }\end{array}$ & 11.1 \\
\hline PV system cost ${ }^{*}\left(\$ / \mathrm{W}_{\mathrm{p}}\right)$ & 7.5 \\
\hline Battery cost $(\$ / \mathrm{kWh})$ & 160 \\
\hline Converter cost $(\$ / \mathrm{kW})$ & 150 \\
\hline Grid power price $(\$ / \mathrm{kWh})$ & 0.12 \\
\hline Interest rate $(\%)$ & 10 \\
\hline Project life time $(\mathrm{yr})$ & 25 \\
\hline
\end{tabular}

As figure 3 shows, for the reference values which resemble current conditions of Iran including power tariff structure and environmental considerations minimum conditions for initiating a participatory power market based on PV system deployment are provided at 25\% reduction of PV system cost and deducted feed-in-tariff more than three times the grid power rate (3.3 times).

Also, in current conditions peak-time sellback price has no effect on feasibility of the market formation, and conversely DG system deployment cannot participate in the grid load-levelling because the PV system has no output at peak hours which are in evening. Moreover, efficiency measures in order to decrease electricity consumption have little effects on levelized cost of energy (COE). However, shoulder sellback price, PV system Capital cost and Interest rate demonstrate intense effects on levelized COE of PV/grid system (Fig. 4).

${ }^{*}$ Domestic market data 


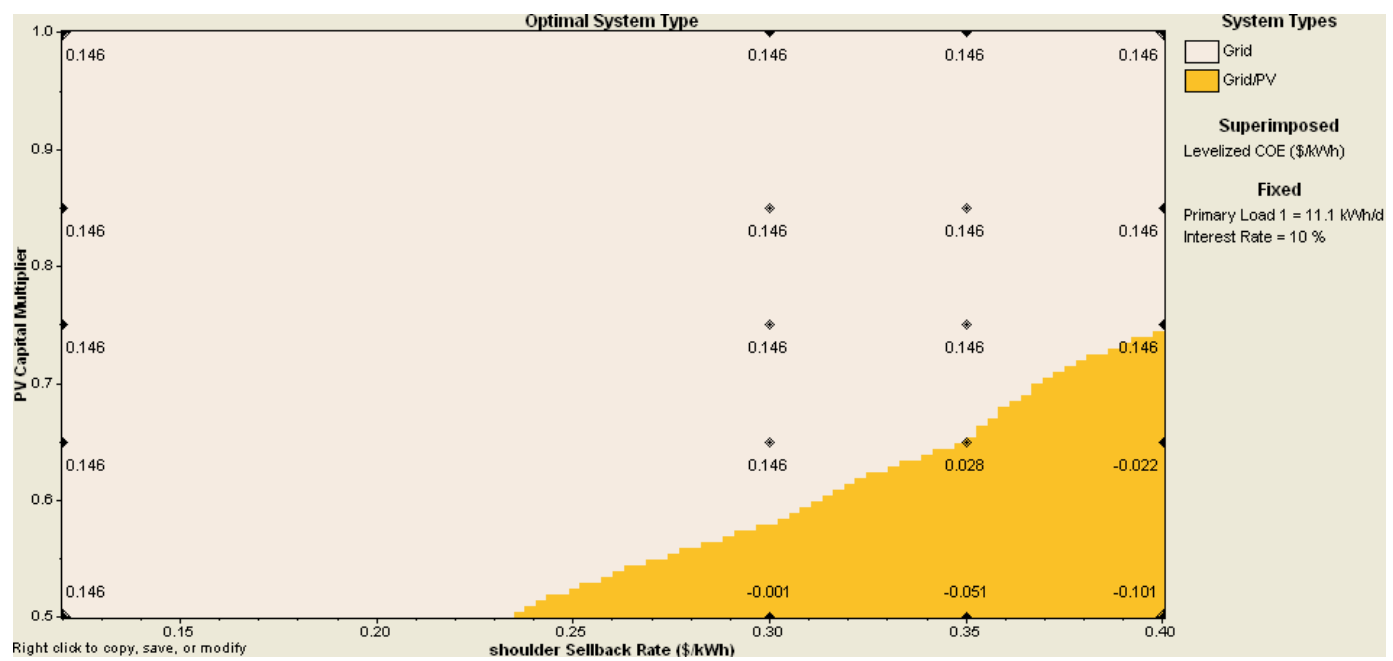

Fig. 3. Feasible area for PV/grid system (Reference case)

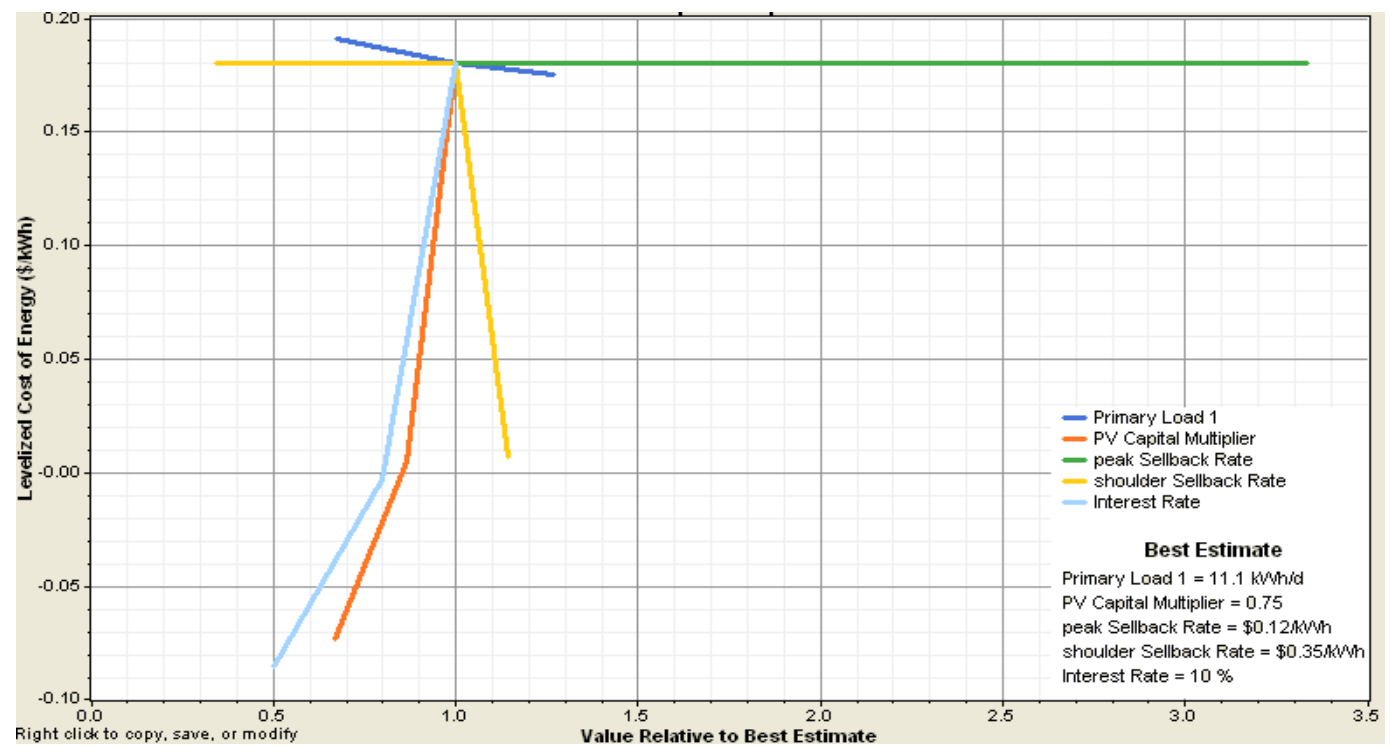

Fig. 4. Efficacy of main parameters on levelized COE (Reference scenario)

But in the second scenario, by virtue of a shift in the peak hours to the day time an incentive arises for PV system utilization because peak hours occur while PV system is producing power. As figure 5 shows, in the second scenario peak-time sellback price has a remarkable impact on levelized COE unlike the reference scenario.

As an intermediate objective the concept of zero energy cost buildings is used to narrow down the way toward a participatory power market. As shown in figure 6 at \%10 interest rate, a minimum feed-in-tariff 1.5 times the grid shoulder-time price at \%50 reduction of PV system cost and 3.3 times the shoulder-time price at $30 \%$ reduction of PV system cost are advisable to achieve the zero power cost building. Table 3 contains levelized COE and net present cost (NPC) for a PV/grid energy system utilized a $6 \mathrm{~kW}_{\mathrm{p}} \mathrm{PV}$ system, in the second scenario at different interest rates including and excluding emission costs. As the results illustrate, taking into account emission costs are in favour of developing PV systems if there exists a positive energy cost balance in favour of the residential building. It means imposing emission penalties helps participatory power market formation if deducted feed-intariffs and interest rate provide enough incentive for deployment of renewable DG systems in zero power cost buildings. Furthermore, as interest rate which is an indicator of whole market has great impact on economic analysis of energy systems, participatory power market formation impressed by economy conditions.

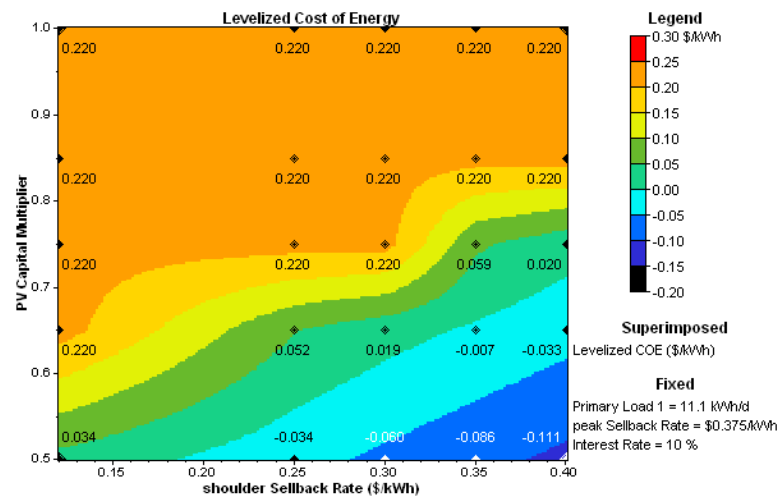

Fig. 6. Levelized COE (second scenario) 


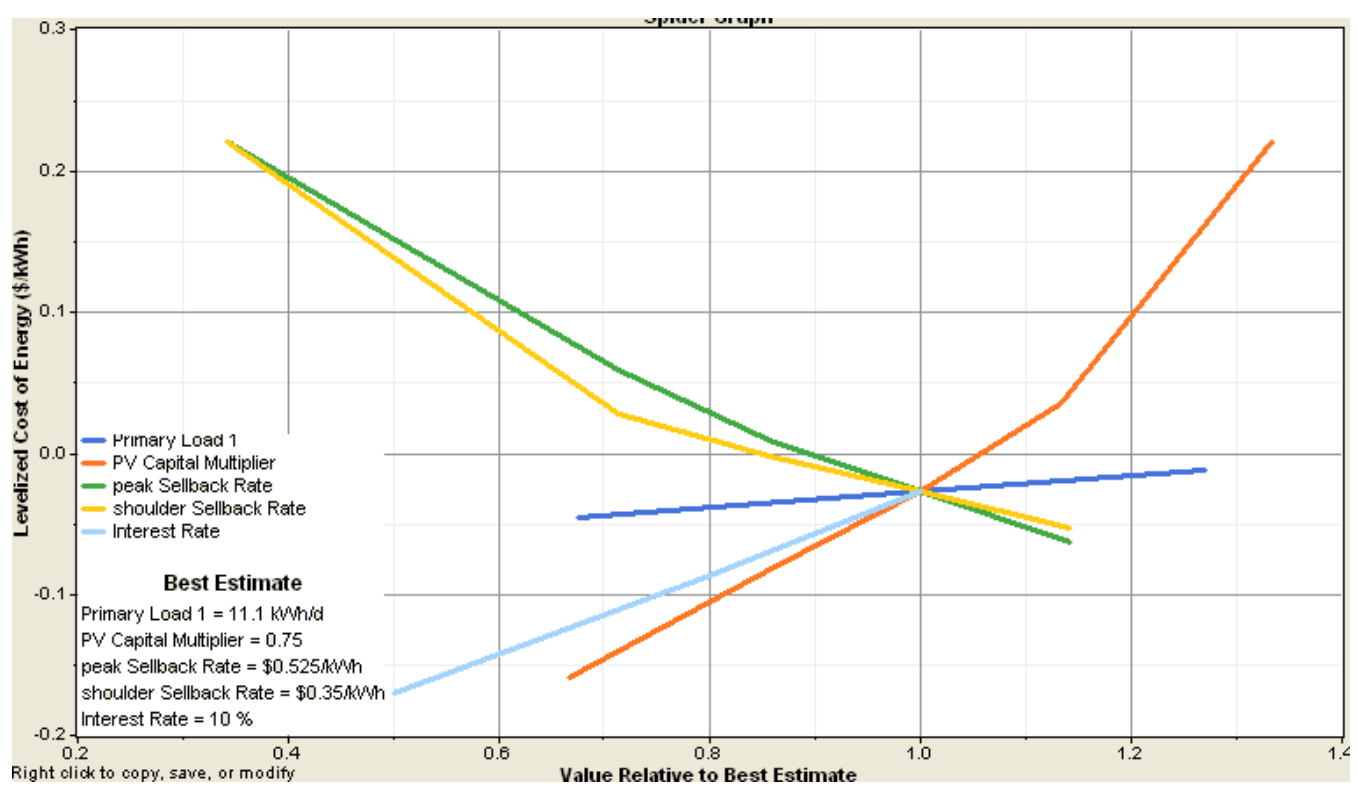

Fig. 5. Efficacy of main parameters on levelized COE ( $2^{\text {nd }}$ scenario)

Table III. - Cost of $6 \mathrm{~kW}_{\mathrm{p}}$ PV system at revised power tariffs

\begin{tabular}{|c|c|c|c|c|c|c|}
\hline \multicolumn{7}{|c|}{ Peak sellback price $=0.375 \$ / \mathrm{kWh}$} \\
\hline $\begin{array}{c}\text { Interest } \\
\text { rate (\%) }\end{array}$ & \multicolumn{2}{|c|}{5} & \multicolumn{2}{|c|}{8} & \multicolumn{2}{c|}{10} \\
\hline & NPC $^{*}$ & $\mathrm{COE}^{\dagger}$ & NPC & COE & NPC & COE \\
\hline $\begin{array}{c}\text { Including } \\
\text { emission } \\
\text { cost }\end{array}$ & -4561 & -0.031 & 5032 & 0.045 & 10382 & 0.110 \\
\hline $\begin{array}{c}\text { Excluding } \\
\text { emission } \\
\text { cost }\end{array}$ & -1559 & -0.011 & 7306 & 0.066 & 11445 & 0.121 \\
\hline
\end{tabular}

\section{Conclusion}

In order to study initial conditions for establishment of a participatory power market in Iran regarding renewable DG systems, a residential PV/grid energy system as a most probable case has been considered. So, a bottom-up approach has been used to avoid rigorous analysis of technical and socio-economic complexities. The results show that PV technology cost, power tariff structure and rating, and interest rate are prominent parameters of the model of market.

As can be seen from figures 3 and 6, grid parity will not be achieved even with 50\% reduction of PV system capital cost, the fact which is in agreement with international reports [11]. Thus, for the mid-term, power tariffs are powerful tools for initiating a power market which encourages renewable DG systems development. Consequently, feed-in-tariff imposed by grid administrator need to be revised. The first useful measure is planning for a shift in peak load time from evening hours to day time, which resembles the conditions that industry and commercial sectors have more contribution in electricity

* $\mathrm{S}$

${ }^{\dagger} \mathrm{S} / \mathrm{kWh}$ consumption. Moreover, interest rate has a great impact on economic analysis of the market (Table III), which is impressed by economy conditions. Furthermore, the results show that imposing emission penalties is in favour of development of the market power which is profited by photovoltaic DG systems if deducted feed-in-tariffs provide necessary incentives for zero power cost buildings outspread.

Although this study has been restricted to one specific building used PV technology, but it can be concluded that development of a participatory power market would occur in a thriving economy. So, Iran must pursue the policy of development of the participatory power market within the economic evolutionary plan.

\section{References}

[1] J.A. Pecas Lopes, N. Hatziagyriou, J. Mutale, P. Djapic, N. Jenkins, "Integrating distributed generation into electric power systems: A review of drivers, challenges and opportunities", Electric Power Systems Research 2007, Vol. 77, pp. 1189-1203.

[2] K. Kowalski, S. Stagl, R. Madlener, I. Omann, "Sustainable energy futures: Methodological challenges in combining scenarios and participatory multi-criteria analysis”, European Journal of Operational Research 2009, Vol. 197, pp. 1063-1074. [3] A. Singh, "Towards a competitive market for electricity and consumer choice in the Indian power sector”, Energy Policy 2010, Vol. 38, pp. 4196-4208.

[4] N. Ahn, V. Niemeyer, "Modeling market power in Korea's emerging power market”, Energy Policy 2007, Vol. 35, pp. 899906.

[5] N. Nabona, A. Pages, "A three-stage short-term electric power planning procedure for a generation company in a liberalized- market”, Electrical Power and Energy Systems 2007, Vol. 29, pp. 408-421.

[6] W. Lise, V. Linderhof, O. Kuik, C. Kemfert, R. Ostling, T. Heinzow, "A game theoretic model of the Northwestern European electricity market- market power and the environment”, Energy Policy 2006, Vol. 34, pp. 2123-2136.

[7] Energy Balance of Iran 2009, Ministry of Energy, Tehran (2010), http://isn.moe.org.ir. 
[8] M. H. Asgari, H. Monsef, "Market power analysis for the Iranian electricity market”, Energy Policy 2010, Vol. 38, pp. 5582-5599.

[9] J. Samimi, "Estimation of height- dependent solar radiation and application to the solar climate of Iran”, Solar Energy 1994, Vol. 52, pp. 401-409.

[10] Technology Roadmaps: Solar photovoltaic energy, International Energy Agency (2010),

http://www.iea.org/publications.

[11] Solar PV Roadmap targets, International Energy Agency

(2010), http://www.iea.org/publications.

[12] National directive of electricity trade in Iran's electricity grid 2005, secretariat of power market regulation, Ministry of Energy, Tehran (2005): In Farsi.

[13] https://analysis.nrel.org/homer

[14] M. Bahadori and A. Mirhossieni, "Clearness Index for Different Cities of Iran”, in Proc. $3^{\text {rd }}$ national conference of Optimization of Fuel Consumption in Buildings 2003, pp. 603621: in Farsi.

[15] Detailed Statistics of Power Industry in Iran: Distribution 2009, Ministry of Energy, Tehran (2010), pp. 6-8: In Farsi. 